\title{
Traumatic Middle Meningeal Artery Pseudoaneurysms Presenting with Intractable Epistaxis: A Rare Case Report and Review of Literature
}

\author{
Jianjun Gu${ }^{1 * \#, ~ J u n ~ L u}{ }^{1 \#, ~ X i a o l i n ~ W a n g 1, ~ Z e h a o ~ L i u ' ~}{ }^{1}$, Guangzhong Gao1, Shiming Zhang ${ }^{2}$ \\ ${ }^{1}$ Departments of Neurosurgery, Taizhou People's Hospital, Taizhou, China \\ ${ }^{2}$ Department of Neurosurgery, The First Affiliated Hospital of Soochow University, Suzhou, China \\ Email: gujianjundt@163.com
}

Received 20 December 2014; accepted 4 January 2015; published 19 January 2015

Copyright (C) 2015 by author and Scientific Research Publishing Inc.

This work is licensed under the Creative Commons Attribution International License (CC BY).

http://creativecommons.org/licenses/by/4.0/

\section{(c) (i) Open Access}

\begin{abstract}
Middle meningeal artery (MMA) pseudoaneurysms are very rare and are most often traumatic. They may present as an epidural or intraparenchymal hematoma. This study reports a rare case in which a patient suffered from intractable epistaxis because of a pseudoaneurysm in middle meningeal artery and skull base fracture after craniocerebra trauma. Pseudoaneurysm and the feeding artery were embolized by using 0nyx-18 liquid embolic system. Complete cessation of bleeding was achieved in this case immediately after the endovascular therapies. In this study, clinical manifestation, diagnostic imaging and endovascular treatment are described. Formation mechanisms and the treatment of traumatic pseudoaneurysm of middle meningeal artery are discussed.
\end{abstract}

\section{Keywords}

Traumatic Pseudoaneurysm, Middle Meningeal Artery (MMA), Epistaxis, Endovascular Treatment

\section{Introduction}

Pseudoaneurysms can arise from the branches of the ECA as well as from the ICA system. However, middle meningeal artery (MMA) pseudoaneurysms are very rare and are most often traumatic. They may present as an epidural or intraparenchymal hematoma [1]. So, it is important to diagnose and treat these aneurysms at the ear-

\footnotetext{
*Corresponding author.

${ }^{\#}$ Equal contributors.
}

How to cite this paper: Gu, J.J., Lu, J., Wang, X.L., Liu, Z.H., Gao, G.Z. and Zhang, S.M. (2015) Traumatic Middle Meningeal Artery Pseudoaneurysms Presenting with Intractable Epistaxis: A Rare Case Report and Review of Literature. Case Reports in Clinical Medicine, 4, 28-31. http://dx.doi.org/10.4236/crcm.2015.41007 
liest to prevent catastrophic events. Recent studies found that traumatic pseudoaneurysms causes intractable epistaxis. Zhang et al. reported that the majority of traumatic pseudoaneurysms of the ICA responsible for massive epistaxes are based on the cavernous segment and the pseudoaneurysms originated from the internal maxillary artery are responsible for some epistaxes [2]. In addition, Li et al. reported a case of traumatic pseudoaneurysm of the basilar artery presenting with fatal epistaxis [3]. But pseudoaneurysm of MMA causing epistaxis has not been reported. This is the first report of a traumatic pseudoaneurysm of the MMA presenting with epistaxis.

\section{Case Report}

A previously healthy 63-year-old man was transferred from a county hospital for severe craniocerebral injury following drifting-down injury. Upon initial examination he was agitated and unable to follow commands, and required to be intubated and sedated. A head computed tomography (CT) scan 1 hour after the accident revealed intracranial pneumatosis (Figure 1(A)), fracture of skull base, right temporal bone fracture, bilateral sphenoid bone fractures, fractures of right zygomatic arch, (Figure 1(B) and Figure 1(C), arrow). The head CT 24 hours after the accident showed right side temporal epidural hematoma and subarachnoid haemorrhage (Figure 1(D)). A little discontinuous nasal bleeding was found after the accident and 2 times of fatal epistaxis happened on 8 days and 10 days after the accident, the amount of bleeding were $800 \mathrm{ml}$ and $1000 \mathrm{ml}$, respectively. And those could be brought to a temporary halt by nasal packing. The patient was transferred to the hospital for cerebral angiogram and further treatment 12 days after the accident. Angiography was performed and demonstrated a traumatic pseudoaneurysm projecting from the right side of middle meningeal artery (Figure 2(A) and (Figure 2(B)). A decision was made to embolise the lesion. Echolen-10 microcatheter was used to select the right MMA through a $5 \mathrm{~F}$ guide catheter. Microcatheter angiograms were obtained to confirm placement and rule out potentially dangerous anastomoses (Figure 2(C)). Pseudoaneurysm and the feeding artery was embolized by using Onyx-18 liquid embolic system. The repeat angiography suggested complete embolism of the pseudoaneurysm (Figure 2(D)). The patient tolerated the procedure well and was subsequently extubated. The patient could be discharged 5 days after endovascular treatment without any neurological deficits. At 6-month follow-up, magnetic
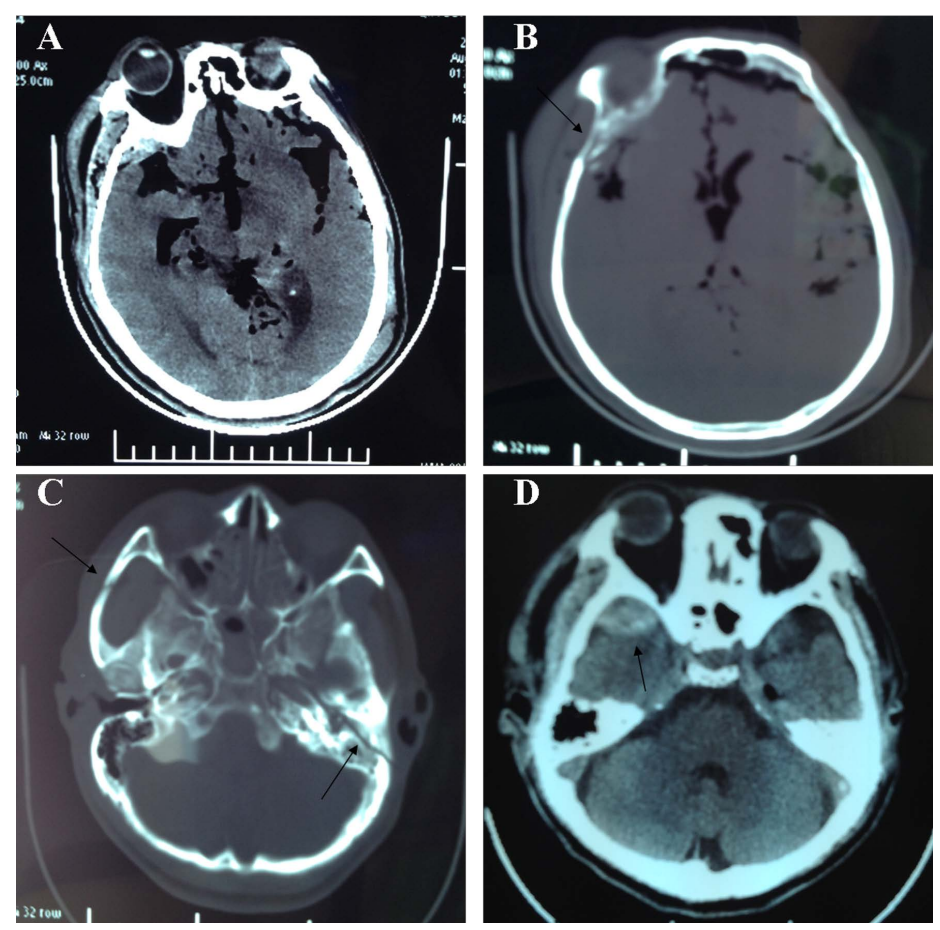

Figure 1. (A) CT scan at admission showing intracranial pneumatosisa; (B) (C) CT scan at admission showing right temporal bone fracture, fracture of skull base, bilateral sphenoid bone fractures, fractures of right zygomatic arch; (D) CT scan 24 hours after the accident showing right sided temporal epidural hematoma. 



Figure 2. (A) Normotopia view of right external carotid artery, demonstrating traumatic pseudoaneurysm arising from middle meningeal artery; (B) Lateral view of right external carotid artery, demonstrating traumatic pseudoaneurysm arising from middle meningeal artery; (C) Microcatheter angiograms rule out potentially dangerous anastomoses; (D) Angiography suggested complete embolism of the pseudoaneurysm.

resonance angiography with contrast showed no evidence of pseudoaneurysm recurrence.

\section{Discussion}

Pseudoaneurysms are less than $1 \%$ of all intracranial aneurysms and mostly associated with a history of trauma [4]. Pseudoaneurysms of the middle meningeal artery (MMA) are rare. About $70 \%-90 \%$ of cases of traumatic MMA pseudoaneurysms are associated with a fracture crossing the MMA in the temporal region [5]. Rupture of traumatic pseudoaneurysms of MMA would cause acute epidural hematoma. Previous studies reported that the prognosis of the rupture of the traumatic pseudoaneurysms was poor, and the mortality rate was $20 \%$ or higher [6] [7]. It is thought that traumatic pseudoaneurysms develop after a small tear in the meningeal artery, which is sealed of by a clot, then recanalize, and form a false lumen. These pseudoaneurysms gradually enlarge and can rupture at any time [7] [8]. Therefore, considering the risk of a secondary rupture, a relatively safe, plausible, and reliable treatment of traumatic pseudoaneurysms must always be carried out without any delay.

The pathology of intractable epistaxis following trauma may involve direct trauma and disruption of vessel or formation of a pseudoaneurysm. The MMA, the dura and the mucosa are likely to be injured as a result of temporal bone and sphenoidal fracture. As a result, epistaxis following a temporal bone fracture may have its haemorrhage source from MMA. Due to arterial damage and consequent pseudoaneurysm formation, patients with epistaxes usually present after a latent period ranging from several days to many years during which there is possible weakening of the arterial wall and/or adjacent bone erosion, with most cases usually presenting at about the third week (88\%) [9] [10]. In this case, patients with epistaxes happened on 8 days and 10 days after the accident, we have a sufficiently high suspicion index for traumatic pseudoaneurysm,then we demonstrated a traumatic pseudoaneurysm projecting from the right sided of middle meningeal artery through angiography. Therefore, as long as the suspicion index for traumatic pseudoaneurysms presenting as intractable epistaxes is suffi- 
ciently high, angiography becomes mandatory [2].

When the traumatic pseudoaneurysm is located in the ECA branches, several treatment options have been reported for these lesions including surgical excision, endovascular treatment with detachable coils or N-butylcyanoacrylate [1]. Selective embolisation to treat traumatic pseudoaneurysms is less invasive and faster than surgical excision. Its advantage is that it is able to demonstrate the feeding vessels and localise the exact anatomic sites of bleeding, offers more distal access to bleeding points, requires a short time for the procedure and allows preservation of other branches of external carotid artery [11]. Therefore, parent artery occlusion may be considered as an effective and a simple procedure for the treatment of pseudoaneurysms [12]. In our case, we obtained to confirm that the pseudoaneurysms were located in middle meningeal artery and rule out potentially dangerous anastomoses through microcatheter angiograms. Therefore, pseudoaneurysm and the parent artery was embolized by using Onyx-18 LES.

\section{Conclusion}

Traumatic pseudoaneurysm should always be suspected in patients with skull base fractures and intractable epistaxes. An endovascular embolization followed by catheter angiography may represent a safe treatment of traumatic middle meningeal artery pseudoaneurysms.

\section{References}

[1] Mehta, S., Alawi, A. and Edgell, R. (2014) E-073 Endovascular Treatment of a traumatic Middle Meningeal Artery Pseudoaneurysm with Onyx LES: A Case Report and Review of Literature. Journal of Neurointerventional Surgery, 6, A73. http://dx.doi.org/10.1136/neurintsurg-2014-011343.140

[2] Zhang, C.W., Xie, X.D., You, C., et al. (2010) Endovascular Treatment of Traumatic Pseudoaneurysm Presenting as Intractable Epistaxis. Korean Journal of Radiology, 11, 603-611. http://dx.doi.org/10.3348/kjr.2010.11.6.603

[3] Li, T., Zhang, Y., Gu, Z., et al. (2013) Traumatic Pseudoaneurysm of the Basilar Artery Presenting with Fatal Epistaxis: A Rare Case Report. Brain Injury, 27, 1316-1319. http://dx.doi.org/10.3109/02699052.2013.812242

[4] Lim, D.H., Kim, T.S., Joo, S.P., et al. (2007) Intracerebral Hematoma Caused by Ruptured Traumatic Pseudoaneurysm of the Middle Menin Geal Artery: A Case Report. Archive of Journal of Korean Neurosurgical Society, 42, 416-418. http://dx.doi.org/10.3340/jkns.2007.42.5.416

[5] Kawaguchi, T., Kawano, T., Kaneko, Y., et al. (2002) Traumatic Lesions of the Bilateral Middle Meningeal Arteries_Case Report. Neurologia Medico-Chirurgica, 42, 221-223. http://dx.doi.org/10.2176/nmc.42.221

[6] Bruneau, M., Gustin, T., Zekhnini, K., et al. (2002) Traumatic False Aneurysm of the Middle Meningeal Artery Causing an Intracerebral Hemorrhage: Case Report and Literature Review. Surgical Neurology, 57, 174-178. http://dx.doi.org/10.1016/S0090-3019(01)00668-1

[7] Wu, X., Jin, Y. and Zhang, X. (2014) Intraparenchymal Hematoma Caused by Rupture of the Traumatic Pseudoaneurysm of Middle Meningeal Artery. Journal of Craniofacial Surgery, 25, e111-e113. http://dx.doi.org/10.1097/SCS.0000000000000450

[8] de Andrade, A.F., Figueiredo, E.G., Caldas, J.G., et al. (2008) Intracranial Vascular Lesions Associated with Small Epidural Hematomas. Neurosurgery, 62, 416-420. http://dx.doi.org/10.1227/01.neu.0000316008.11388.f2

[9] Chen, D., Concus, A.P., Halbach, V.V., et al. (1998) Epistaxis Originating from Traumatic Pseudoaneurysm of the Internal Carotid Artery: Diagnosis and Endovascular Therapy. Laryngoscope, 108, 326-331. http://dx.doi.org/10.1097/00005537-199803000-00004

[10] Fontela, P.S., Tampieri, D., Atkinson, J.D., et al. (2006) Posttraumatic Pseudoaneurysm of the Intracavernous Internal Carotid Artery Presenting with Massive Epistaxis. Pediatric Critical Care Medicine, 7, 260-262. http://dx.doi.org/10.1097/01.PCC.0000216418.01278.5E

[11] Singam, P., Thanabalan, J. and Mohammed, Z. (2011) Superselective Embolisation for Control of Intractable Epistaxis from Maxillary Artery Injury. Biomedical Imaging and Intervention Journal, 7, e3.

[12] Song, H.H., Won, Y.D., Kim, Y.J., et al. (2008) The Endovascular Management of Saccular Posterior Inferior Cerebellar Artery Aneurysms. Korean Journal of Radiology, 9, 396-400. http://dx.doi.org/10.3348/kjr.2008.9.5.396 
Scientific Research Publishing (SCIRP) is one of the largest Open Access journal publishers. It is currently publishing more than 200 open access, online, peer-reviewed journals covering a wide range of academic disciplines. SCIRP serves the worldwide academic communities and contributes to the progress and application of science with its publication.

Other selected journals from SCIRP are listed as below. Submit your manuscript to us via either submit@scirp.org or Online Submission Portal.
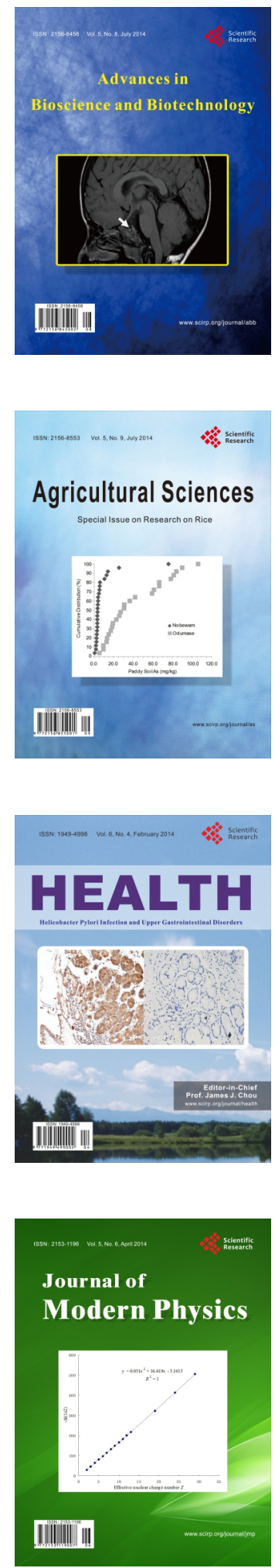
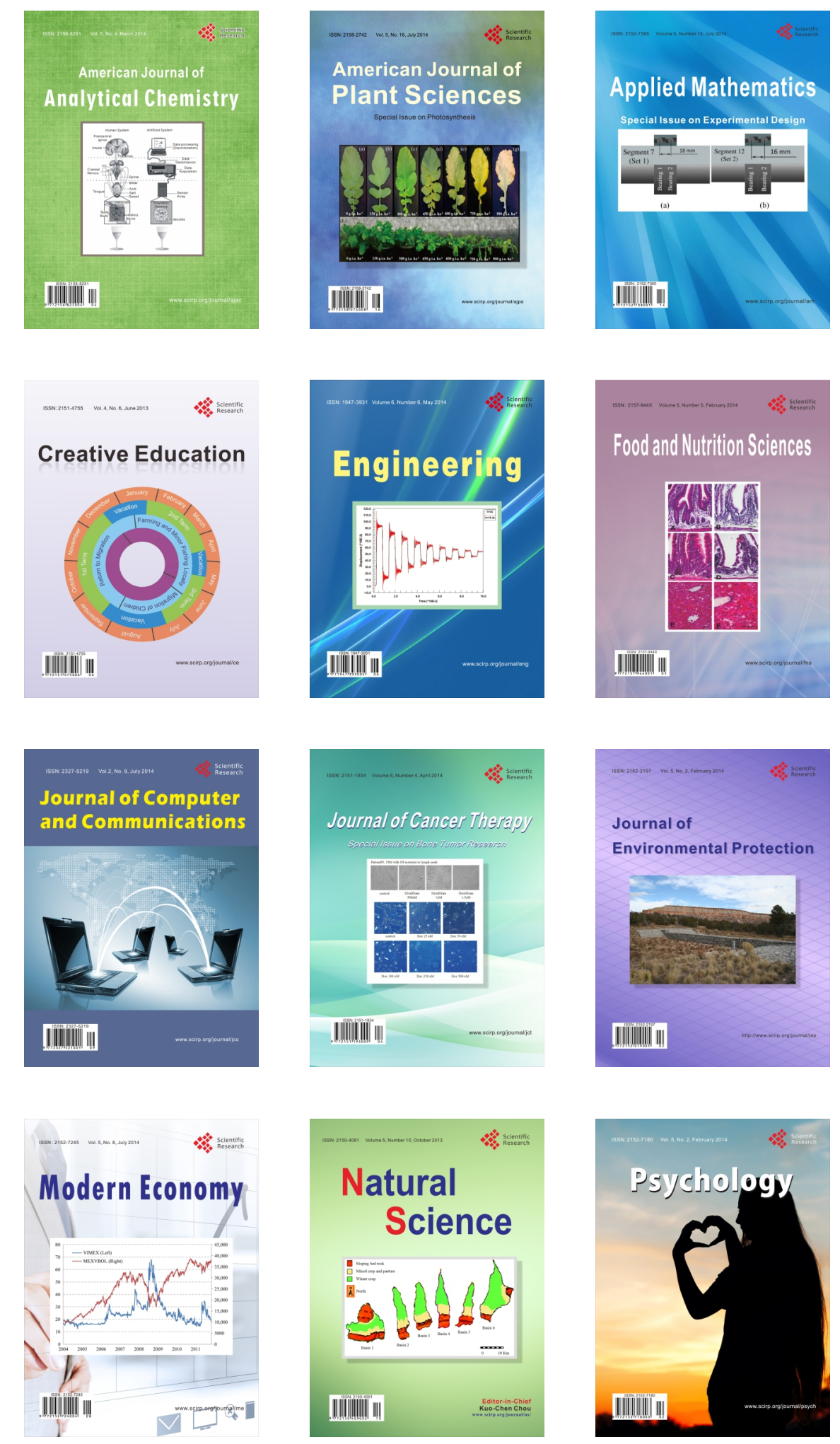